\title{
Micro-stratification of malaria risk in Nepal: implications for malaria control and elimination
}

Komal Raj Rijal ${ }^{1}$, Bipin Adhikari ${ }^{2}$, Nabaraj Adhikari ${ }^{1}$, Shyam Prakash Dumre ${ }^{3}$, Mayur Sharma Banjara ${ }^{4}$, Upendra Thapa Shrestha', Megha Raj Banjara ${ }^{1}$, Nihal Singh ${ }^{5}$, Leonard Ortegea ${ }^{6}$, Bibek Kumar Lal', Garib Das Thakur ${ }^{7}$ and Prakash Ghimire ${ }^{1,5^{*}}$

\begin{abstract}
Background: A significant reduction in malaria cases over the recent years in Nepal has encouraged the government to adopt a goal of "malaria-free nation by 2025." Nevertheless, to achieve this goal, it is critical to identify the epidemiological burden of malaria by specific regions and areas for an effective targeted intervention. The main objective of this study was to estimate the risk of malaria at Village Development Committee (VDC) level in Nepal based on disease, vector, parasite, and geography.

Methods: In 2012, the micro-stratification of malaria risk was carried out in 75 districts of Nepal. Instruments such as a questionnaire, case record forms, and guidelines for malaria micro-stratification were developed and pre-tested for necessary adaptations. Village Development Committee (VDC)-wise malaria data were analyzed using exploratory statistics and were stratified by geographical variables that contributed to the risk of malaria. To understand the transmission risk at VDC level, overlay analysis was done using ArcGIS 10. To ensure transparent, reproducible, and comprehensible risk assessment, standard scoring method was selected and utilized for data from 2009 to 2011 . Thus identified, three major variables (key determinants) were given weights (wt.) accordingly to stratification of the malaria risk (disease burden, "0.3" wt.; ecology/vector transmission, "0.5" wt.; and vulnerability-population movement, "0.2" wt.). Malaria risk in a VDC was determined based on the overall scores and classified into four categories: no risk, low risk, moderate risk, and high risk.
\end{abstract}

Results: Analyzing the overall risk based on scoring of the total VDCs $(n=3976), 54(1.36 \%), 201(5.06 \%), 999$ (25.13\%), and 2718 (68.36\%) were identified as high-, moderate-, low-, and no-risk categories for malaria, respectively. Based on the population statistics, 3.62\%, 9.79\%, 34.52\%, and 52.05\% of the country's total population live in high-risk, moderaterisk, low-risk, and no-risk VDCs for malaria, respectively. Our micro-stratification study estimates are 100,000 population at high risk. Regional distribution showed that the majority of the high-risk VDCs were identified in the Far- and Midwestern regions (19 and 18 VDCs) followed by Central and Western regions (10 and 7 VDCs) with no high-risk VDCs in the Eastern region. Similarly, 77, 59, 27, 24, and 14 VDCs of the Central, Mid-western, Western, Eastern, and Far-western regions, respectively, were found under moderate malaria risk. Of the low-risk VDCs, 353, 215, 191, 148, and 92 were respectively from the Central, Eastern, Western, Far-western, and Mid-western regions.

(Continued on next page)

\footnotetext{
* Correspondence: prakashghimire@gmail.com

${ }^{1}$ Central Department of Microbiology, Tribhuvan University, Kirtipur, Kathmandu, Nepal

${ }^{5}$ World Health Organization (WHO), Country Office, Kathmandu, Nepal

Full list of author information is available at the end of the article
}

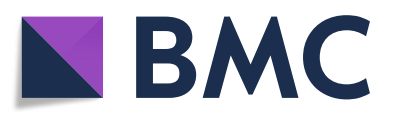

(c) The Author(s). 2019 Open Access This article is distributed under the terms of the Creative Commons Attribution 4.0 International License (http://creativecommons.org/licenses/by/4.0/), which permits unrestricted use, distribution, and reproduction in any medium, provided you give appropriate credit to the original author(s) and the source, provide a link to the Creative Commons license, and indicate if changes were made. The Creative Commons Public Domain Dedication waiver (http://creativecommons.org/publicdomain/zero/1.0/) applies to the data made available in this article, unless otherwise stated. 
(Continued from previous page)

Conclusions: The current micro-stratification study provides insights on malaria risk up to the VDC level. This will help the malaria elimination program to target interventions at the local level thereby ensuring the best utilization of available resources to substantially narrowed-down target areas. With further updates and refinement, the microstratification approach can be employed to identify the risk areas up to smaller units within the VDCs (ward and villages).

Keywords: Malaria, Micro-stratification, Elimination, Intervention, Nepal

\section{Background}

Malaria, caused by Plasmodium species, remains one of the major global health problems, causing nearly half million deaths per year. Malaria is endemic in 91 countries and territories in tropical and sub-tropical zones, spanning all continents of the world (except Antarctica and Australia), with transmission intensities ranging from very low to extremely high [1].

Between 2010 and 2015, malaria incidence among populations at risk (the rate of new cases) fell by $21 \%$ globally. In that same period, malaria mortality rates among populations at risk fell by $29 \%$ globally among all age groups and by $35 \%$ among children under 5 [2].

In recent years, an increasing number of countries such as Armenia, Maldives, Morocco, Turkmenistan, and the United Arab Emirates with low and moderate transmission areas eliminated malaria from their entire territory [3]. With the renewed multi-sectoral efforts and commitment, Southeast Asia region has some of the most pronounced malaria declines, with 5 countries out of 11 reporting decrease of more than $75 \%$ of cases from 2000 to 2012 [4]. These figures are encouraging for countries embarking towards malaria elimination.

Overall malaria trend in Nepal for the last 5 years indicates a decline of both clinical and confirmed malaria cases [5]. The country has exceeded the Millennium Development Goals in 2010 (set for 2015) to reduce malaria morbidity and mortality and is in a unique position to move towards elimination [5]. With the significant reduction in malaria burden, the Nepal malaria program has set up the vision of a malaria-free Nepal by 2025 and the country is currently in the pre-elimination phase [6].

At all endemic districts, there is a significant variation in malaria risk by regions, areas, and villages and they are largely dependent upon the local context. Thus, it is unlikely that a one-size-fits-all strategy will be appropriate for all endemic settings within a country [7]. This situation echoes Nepal's current malaria epidemiology, where the risk of contracting malaria is highly variable from district to district and even between areas within the district [8]. In addition, within a district, the heterogeneity in malaria incidence and transmission is likely to complicate the interventions. Risk stratification will therefore be a key to tailoring the interventions within a country. Definition of priority areas for malaria control interventions should be based on the analysis of risk determinants related to the human host, parasite, and the vectors that together determine transmission intensity [7].

To date, Nepal has been implementing malaria control interventions targeting an entire district without selecting specific areas, despite that the risk varies within a district. An independent external assessment team commissioned by the World Health Organization (WHO) in 2010/2011 strongly recommended to update the existing stratification of malaria risk areas as early as possible [9]. Malaria risk mapping by micro-stratification up to the Village Development Committee (VDC) level was recommended in order to deploy appropriate and effective malaria control interventions to achieve a goal of malaria elimination by 2025 . The main objective of this study was to estimate the risk of malaria at the VDC level in Nepal based on disease, vector, parasite, and geography.

\section{Materials and methods Study setting}

Nepal has three main ecological zones (five ecological settings), mountain (middle- and high-range mountain), hill, and Terai (outer and inner Terai), running from west to east intersected by rivers flowing from north to south. In 2011, the population was estimated to be 26.6 million with an average family size of 4.9 persons. The annual population growth rate is $1.35 \%$. An estimated $>1.9$ million Nepali citizens, mostly male laborers, work outside of the country in India, the Middle East, and other countries, who upon return, contribute to the significant number of imported malaria cases. The four human malaria species are not evenly spread across the malaria-affected areas of Nepal. P. vivax is the most common species and predominates across all ecological settings, whereas $P$. falciparum predominates in the forest fringe, forest, foothills, and inner Terai. Urbanization continues to occur at a rapid pace, includes malaria endemic areas, and contributes to changing malaria transmission ecology.

\section{Study participants and study sites}

The micro-stratification assessment was carried out in two phases: (a) in the first phase in 31 districts which reported 
more than $92 \%$ of malaria and $96 \%$ of $P$. falciparum of the total confirmed cases in the country and (b) in the second phase in the remaining 44 districts with few or no malaria cases $(<10 \%$ of total malaria cases).

\section{Study tools}

Study tools were developed in consultation with experts. The VDC-based questionnaire had two parts. The first part included demographic, geo-ecological, meteorological, socioeconomic, and entomological information. The second part included malaria disease, diagnosis and treatment, classification, severity/death, drug resistance status, containment information, and vector control. Pre-testing of the developed documents was carried out in one Primary Health Center (PHC) of the Kavre district and was followed by necessary amendments, finalization, and endorsement.

\section{Data collection}

Micro-stratification teams were formed at three levels with clear reporting network at central, regional, and district levels to ensure credible data on basic malaria information by VDC/municipality (Fig. 1). The central team was composed of experts from the Epidemiology Diseases Control Division (EDCD), WHO country/regional offices, and other technical organizations. The central team collected essential data from the Central Bureau of Statistics, Department of Forestry, Department of Hydrology and Meteorology, Department of Local Development, and International Centre for Integrated
Mountain Development (ICIMOD) and additional information from various organizations of national and international experts.

Five regional and 75 district teams were formed for data collection. Each regional team was led by an experienced entomologist, a data manager, and a lab technician and was supported by district teams (composed of district health officer/district public health officer (DHO/DPHO)). Both regional and district teams were apprised in advance on their roles and responsibilities in the assessment process of data that included collection, verification, validation, and compilation at the district and their collation at the center. A bi-directional line of communication mechanism was established between teams at all levels for efficient reporting and feedback.

Data was collected from April to September 2012. The regional teams were deployed at the districts for data collection and coordination with the district teams.

\section{Data management}

Collected data, including field reports by the regional teams, were validated using multiple mechanisms to ensure its credibility by the central team.

The accuracy of data was verified by the members of the central team and the EDCD through monitoring visits on selected study sites.

A central database was established at EDCD consisting VDC level basic malaria information collected by the regional teams, population data, long-lasting insecticidetreated nets (LLINs) distribution data, drug resistance

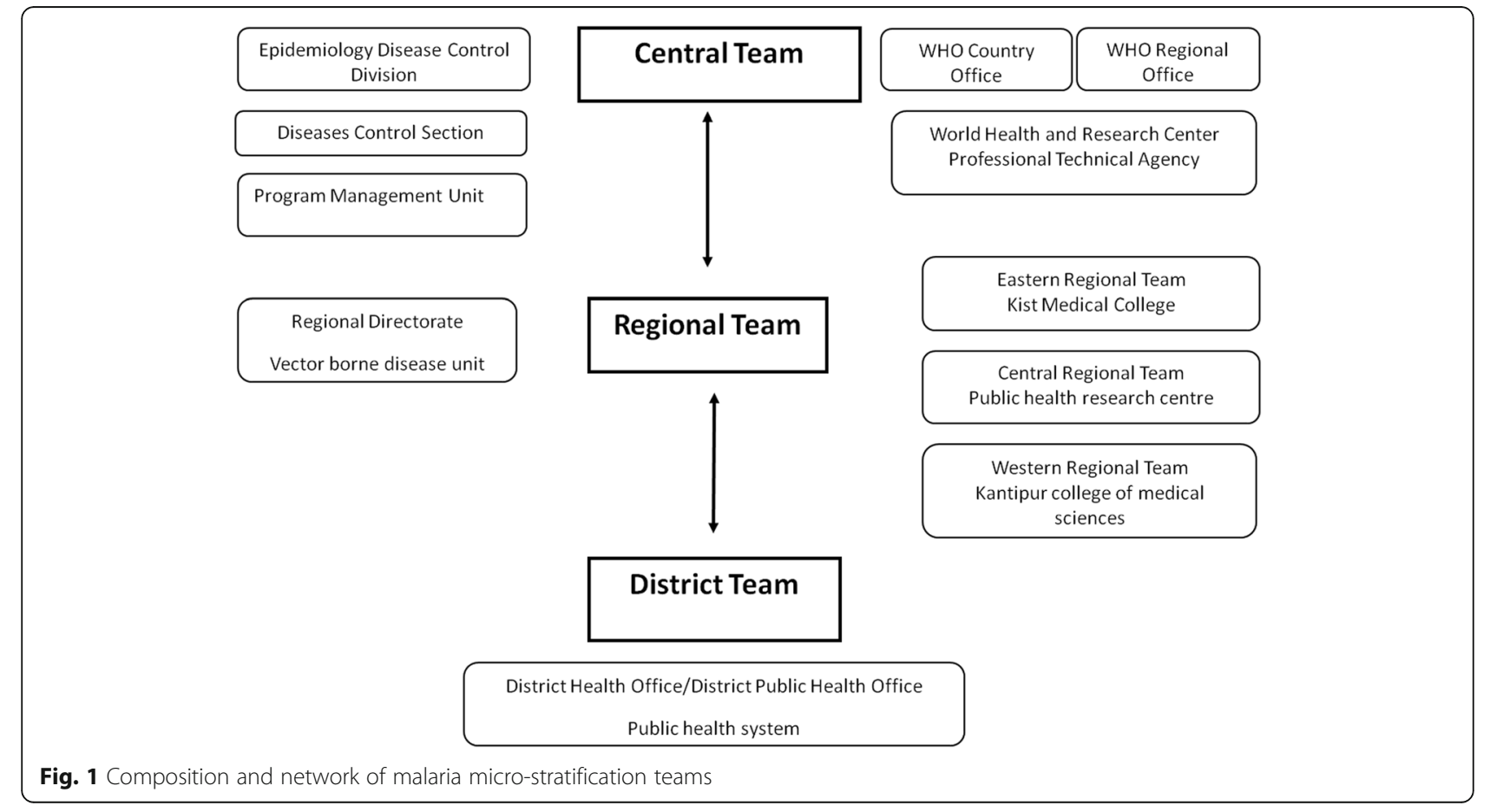


information from national experts, data regarding altitude (elevation) and land use from International Centre for Integrated Mountain Development (ICIMOD), data from the Department of Meteorology and Hydrology, and data from the meta-analysis of existing malaria entomological reports generated by workshop (Fig. 2).

\section{Data analysis}

\section{Key determinants for risk analysis}

VDC-wise basic malaria information was analyzed using exploratory statistics such as frequency and percentage in addition to geographical information system (GIS) to identify variables that contribute to malaria risk in Nepal. Three major variables (key determinants) were used: (i) disease burden average Annual Parasite Index (API-a), malaria cases per 1000 risk population; (ii) entomological risk at various ecological settings, ecology, and malaria vectors; and (iii) vulnerability and population movement.

\section{Interpretation of data}

Collected data was reviewed during a workshop on "Micro-stratification of malaria risk based on entomological findings in different ecological settings of Nepal." The workshop was participated by senior malariologists, entomologists, and malaria control experts. All relevant documents were collected and interpreted. All available documents at EDCD and Vector Borne Disease Research and Training Center (VBDRTC), including papers published in national and international journals $[10,11]$, WHO reports [12], malaria entomological annual reports [13], personal collections, and other unpublished data, were scrutinized for vector characteristics and their bionomics in relation to malaria transmission. Each document was reviewed by individual experts and was followed by a focused group discussion to draw conclusion.

The workshop documented the characteristics of different malaria vectors and stratified the malaria risk according to the transmission potential of malaria vectors of Nepal in different ecological settings (Table 1; Fig. 3).

\section{Geographical information system analysis}

To identify transmission risk at VDC level, overlay analysis was done in GIS environment using ArcGIS 10. Three GIS data layers, (i) land use derived from Thematic Mapper (TM), 2010; (ii) VDC boundary; and (iii) ecological zone, were overlaid. A VDC was considered in an ecological zone if a major part of the VDC fell in the zone. The same principle was applied for land use. A special consideration was given to the VDCs, which reported cases in all 3 years (2009 to 2011), showing the persistence of transmission, mostly in the inner Terai region, and was overlaid to further refine the malaria transmission risk by ecological settings.

\section{Risk assessment and scoring method}

Scoring methodology was selected to obtain cumulative risk after reviewing available analysis methods to ensure transparency, reproducibility, and comprehensibility of risk assessment. The methodology of assessment tool devised by the Center for Disease Control and Prevention (CDC), USA [14] was adopted to identify areas of malaria risk in Nepal. Each indicator establishes a weight (wt.) and then multiplies the weight by the response value to obtain a weighted value for each indicator. These weighted values were combined to construct the "overall risk score." This methodology is implemented through different steps. Both qualitative and quantitative variables are converted to qualitative variables. A fourpoint Likert-type response is assigned to each variable. The assessment tool is presented in (Table 2).

After the careful evaluation of four different scoring methods (applying different scores to different variables), it was decided on assigning (i) disease burden average API-a "0.3" wt., (ii) ecology-vector and transmission risk-a

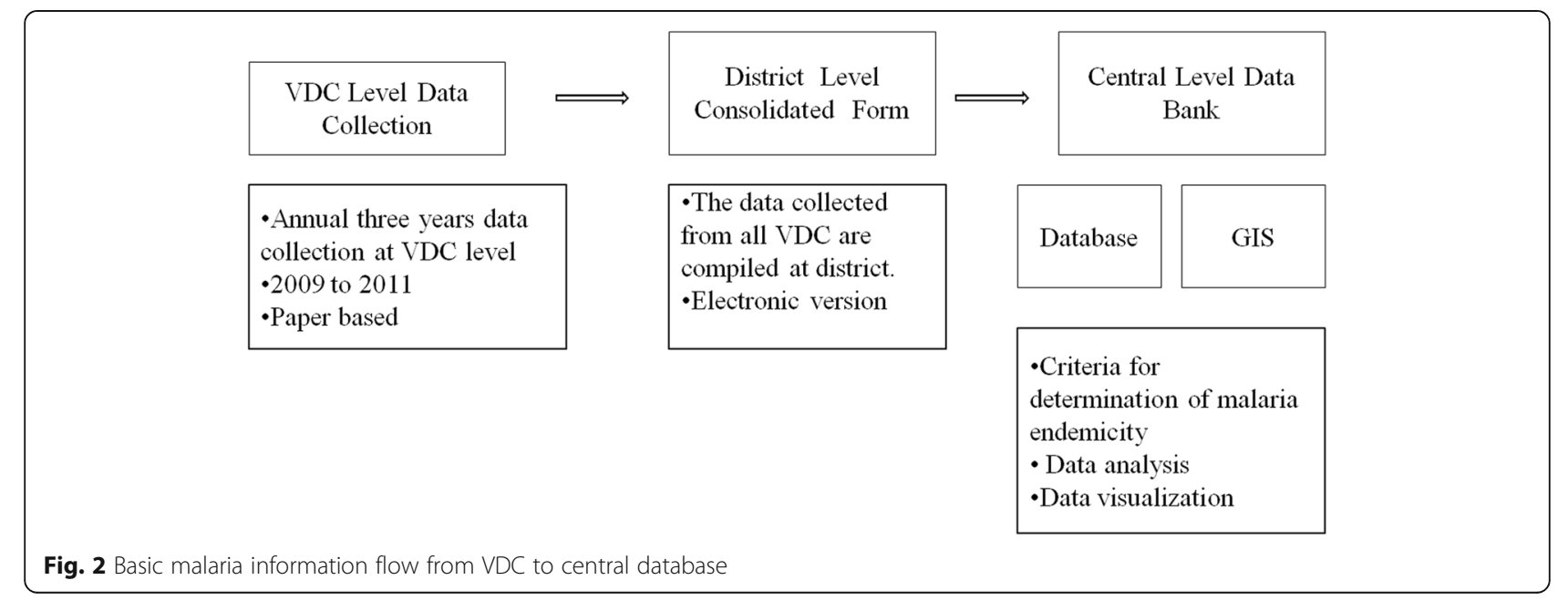


Table 1 Entomological stratification of malaria transmission risk in different ecological settings of Nepal

\begin{tabular}{|c|c|c|c|c|c|c|c|c|c|c|c|c|}
\hline \multicolumn{13}{|c|}{ Entommological stratification of malaria transmission risk in different eco-zones } \\
\hline \multirow{2}{*}{ Eco-Zones } & \multirow{2}{*}{ Vector/s } & \multicolumn{3}{|c|}{$\begin{array}{c}\text { Seasonal } \\
\text { prevalence/months }\end{array}$} & \multirow{2}{*}{\begin{tabular}{c|} 
Host Preference \\
$\begin{array}{c}\text { Anthropophilic or } \\
\text { Zoophilic }\end{array}$ \\
\end{tabular}} & \multicolumn{3}{|c|}{ Biting rhythm hrs } & \multirow{2}{*}{$\begin{array}{c}\begin{array}{c}\text { Resting and } \\
\text { feeding } \\
\text { behaviour }\end{array} \\
\end{array}$} & \multirow{2}{*}{ Breeding habitat } & \multirow{2}{*}{$\begin{array}{l}\text { Susceptibility to } \\
\text { insecticides }\end{array}$} & \multirow{2}{*}{ Transmission risk * } \\
\hline & & Start & Peak & End & & Start & End & Peak & & & & \\
\hline \begin{tabular}{|c|} 
Outer Terai \\
Plain cultivated \\
land(Rice eco- \\
system)
\end{tabular} & \begin{tabular}{|l|} 
An. \\
anularis
\end{tabular} & March & Aug & Nov & Zoophilic & 7:00 PM & 5:00AM & $11: 00 P M$ & \begin{tabular}{|l|} 
Endophagic- \\
Exophilic
\end{tabular} & Pond, paddy fields & \begin{tabular}{|l|} 
Resistant to \\
DDT,BHC\&Susceptibl \\
e to OP \& Synthetic \\
pyrethroids
\end{tabular} & Low Risk \\
\hline \multirow{2}{*}{$\begin{array}{c}\text { Outer Terai- } \\
\text { Forest } \\
\text { fringe,Forested } \\
\& \text { foothills(Fluvi } \\
\text { ecosystem) }\end{array}$} & \begin{tabular}{|l|} 
An. \\
Fluvitialis
\end{tabular} & Feb & May & Dec & $\begin{array}{c}\text { Indiscriminate } \\
\text { (Anthropophilic } \\
\text { \&Zoophilic both) }\end{array}$ & 7:00PM & 5:00AM & 10:00PM & \begin{tabular}{|l|} 
Endophagic- \\
exophilic, or \\
exophagic- \\
exophilic
\end{tabular} & $\begin{array}{l}\text { Slow running,clear } \\
\text { water with marginal } \\
\text { and emergent } \\
\text { vegetation }\end{array}$ & $\begin{array}{l}\begin{array}{l}\text { Susceptibile to all } \\
\text { insecticides }\end{array} \\
\text { inside }\end{array}$ & $\begin{array}{l}\text { High (Perenneal } \\
\text { transmission)\&High to } \\
\text { moderate transmission }\end{array}$ \\
\hline & \begin{tabular}{|l|} 
An. \\
maculatus
\end{tabular} & Feb & May & Dec & Zoophilic & 6:00PM & 2:00AM & 9:00PM & \begin{tabular}{|l|} 
Endophagic - \\
Exophallic
\end{tabular} & $\begin{array}{l}\text { Slow running, clear } \\
\text { water with } \\
\text { marginal, emergent } \\
\text { vegetation \& } \\
\text { shallow rice field } \\
\end{array}$ & $\begin{array}{l}\text { Susceptibile to all } \\
\text { insecticides }\end{array}$ & Low \\
\hline \multirow[t]{2}{*}{$\begin{array}{l}\text { Inner Terai } \\
\text { (Forest } \\
\text { ecosystem) }\end{array}$} & An.fluvitia & Feb & $\begin{array}{l}\text { Mar- } \\
\text { April, } \\
\text { Oct- } \\
\text { Dec }\end{array}$ & Dec & $\begin{array}{c}\text { Indiscriminate } \\
\text { (Anthropophilic } \\
\text { \&Zoophilic both) }\end{array}$ & 7:00PM & $5: 00 \mathrm{AM}$ & 10:00PM & \begin{tabular}{|l|} 
Endophagic- \\
Exophilic, or \\
Exophagic- \\
Exophillic \\
\end{tabular} & \begin{tabular}{|l|} 
Slow \\
running,clearwater \\
with marginal and \\
emergent vegetation
\end{tabular} & \begin{tabular}{|l|}
$\begin{array}{l}\text { Susceptibile to all } \\
\text { insecticides }\end{array}$ \\
\end{tabular} & $\begin{array}{l}\text { High (Perenneal } \\
\text { transmission)\&High to } \\
\text { moderate transmission }\end{array}$ \\
\hline & \begin{tabular}{|l|} 
An. \\
maculatus
\end{tabular} & Feb & May & Oct & Zoophilic & 6:00PM & 2:00AM & 9:00PM & \begin{tabular}{|l|} 
Endophagic - \\
Exophillic
\end{tabular} & $\begin{array}{l}\text { Slow running,clear } \\
\text { water with } \\
\text { marginal, emergent } \\
\text { vegetation \& } \\
\text { shallow rice field } \\
\end{array}$ & $\begin{array}{l}\text { Susceptibile to all } \\
\text { insecticides }\end{array}$ & Moderate to Low \\
\hline \multirow[t]{2}{*}{\begin{tabular}{c|} 
Hills\&hills river \\
valleys ( Hill - \\
river-ecosystem)
\end{tabular}} & \begin{tabular}{|l|} 
An. \\
fluvitialis,
\end{tabular} & Mar & Aug & Oct & Indiscriminate & 7:00PM & 5:00AM & 10:OOPM & \begin{tabular}{|l|} 
Endophagic- \\
Exophilic,or \\
Exophagic- \\
Exophilic \\
\end{tabular} & \begin{tabular}{|l|} 
Slow \\
running,clearwater \\
with marginal and \\
emergent vegetation
\end{tabular} & $\begin{array}{l}\text { Susceptibile to all } \\
\text { insecticides }\end{array}$ & $\begin{array}{l}\text { Low (Transmission } \\
\text { period short) }\end{array}$ \\
\hline & \begin{tabular}{|l|}
$\begin{array}{l}\text { An. } \\
\text { maculatus }\end{array}$ \\
\end{tabular} & Mar & Aug & Oct & Zoophilic & 6:00PM & $2: 00 \mathrm{AM}$ & 9:00PM & \begin{tabular}{|l|} 
Endophagic - \\
Exophillic
\end{tabular} & \begin{tabular}{|l|} 
Slow \\
running,clearwater \\
with marginal, \\
emergent vegetation.
\end{tabular} & $\begin{array}{l}\begin{array}{l}\text { Susceptibile to all } \\
\text { insecticides }\end{array} \\
\end{array}$ & \begin{tabular}{|l|} 
Low (Transmission \\
period short Jun-Oct)
\end{tabular} \\
\hline $\begin{array}{c}\text { Mountain and } \\
\text { upper river } \\
\text { valleys(Hill- } \\
\text { river-eco- } \\
\text { system) }\end{array}$ & \begin{tabular}{|l|} 
An. \\
maculatus
\end{tabular} & Jun & Aug & Sep & Zoophilic & 6:00PM & 2:00AM & 9:00PM & \begin{tabular}{|l|} 
Endophagic - \\
Exophillic
\end{tabular} & \begin{tabular}{|l|} 
Slow \\
running,clearwater \\
with marginal, \\
emergent vegetation \\
$\&$ (terrace type of \\
farming)
\end{tabular} & $\begin{array}{l}\text { Susceptibile to all } \\
\text { insecticides }\end{array}$ & $\begin{array}{l}\text { Transmission period } \\
\text { very short (July-sept) } \\
\text { Low }\end{array}$ \\
\hline
\end{tabular}

*Risk criteria for malaria transmission is adapted as per recommendation made by Dr. G.B. White in 1982

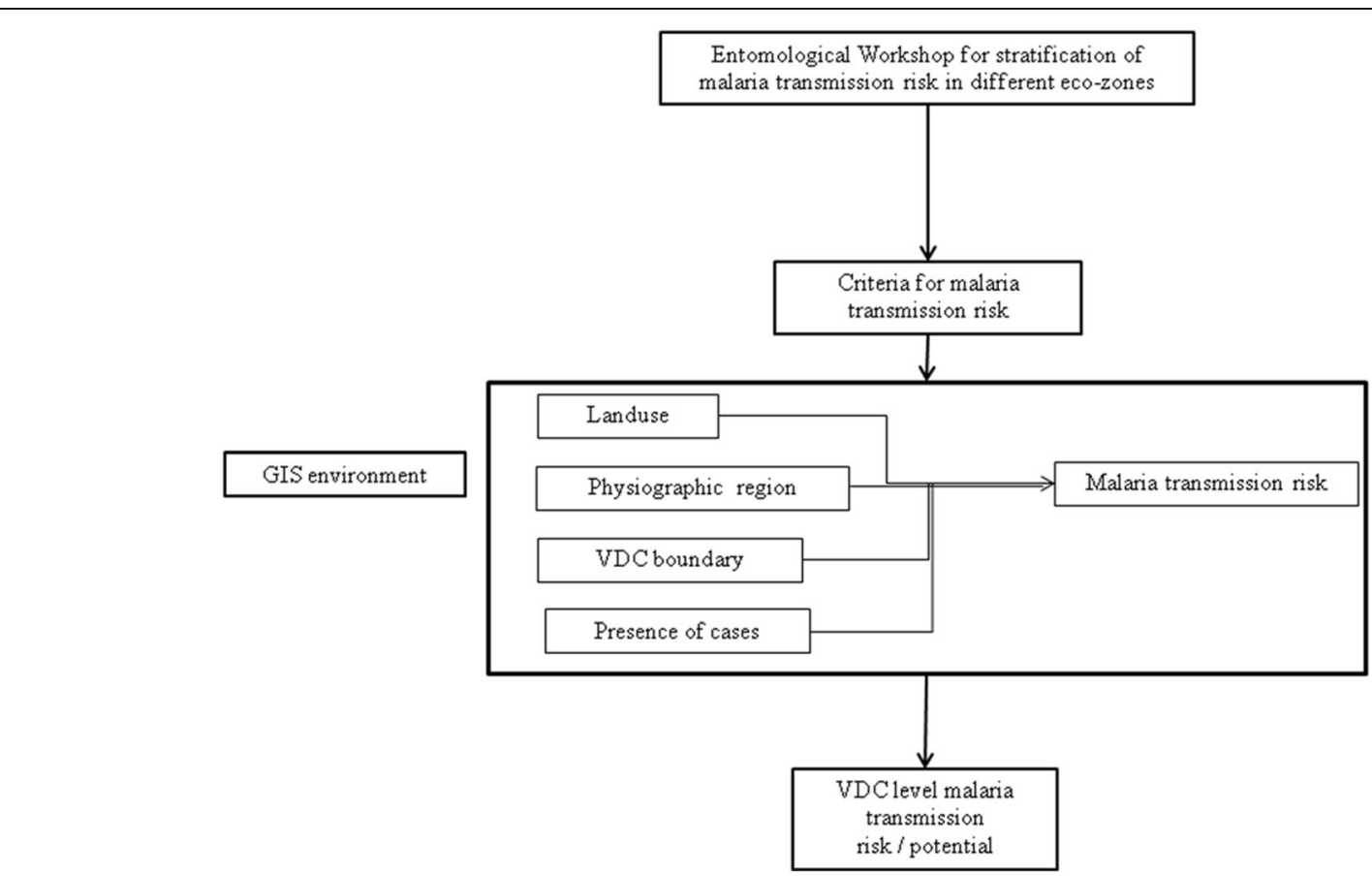

Fig. 3 Flowchart showing steps to derive transmission risk by ecological setting 
Table 2 Scoring methodology for micro-stratification of malaria risk in Nepal

\begin{tabular}{|c|c|c|c|c|}
\hline Level 1 & Overall risk & Sum of level $2 \times 100 \%$ & & \\
\hline $\begin{array}{l}\text { Level } 2 \\
\text { response* wt. }\end{array}$ & $\begin{array}{l}\text { Indicators } \\
\text { (wt.) }\end{array}$ & Disease burden (0.3) & Ecology (0.5) & Vulnerability (0.2) \\
\hline Level 3 & $\begin{array}{l}\text { Variable } \\
\text { response }\end{array}$ & API in 3 years & Transmission risk & Population movement \\
\hline Response value & $\begin{array}{l}\text { High (1.0)-H } \\
\text { Mod (0.6)-M } \\
\text { Low }(0.1)-\mathrm{L} \\
\text { No }(0.0)-\mathrm{N}\end{array}$ & $\begin{array}{l}\text { Average API } \geq 1.0-\mathrm{H} \\
\text { Average API } 0.01 \text { to } \\
0.99-\mathrm{M} \\
\text { Average API is } 0-\mathrm{L}\end{array}$ & $\begin{array}{l}\text { Combination of geo-ecosystem } \\
\text { and vector species } \\
\text { (refer Table 1) }\end{array}$ & $\begin{array}{l}\text { - Frequent movement to forests and development areas } \\
\text { (high risk) - H } \\
\text { - Visit to forest is infrequent but visit to high risk areas is } \\
\text { frequent (moderate risk) - M } \\
\text { - Movements to above areas are infrequent but endemic } \\
\text { areas in Nepal or India is frequent (low risk) - } \mathrm{L} \\
\text { - Movement to non-endemic areas only (no risk) - N }\end{array}$ \\
\hline
\end{tabular}

*Level 2 response was categorized by a total of $100 \%$

" 0.5 " wt., and (iii) vulnerability-population movement-a " 0.2 " wt. Utilizing this method, we provided much weight on ecology and transmission risk and it was considered epidemiologically credible because of the transmission risk potential that depends on ecology, vector, and transmission environment. Moreover, the main objective of micro-stratification was to delineate the areas according to the grade (level) of the risk of malaria transmission.

\section{Operational definition of risk}

High-risk districts of Nepal are 25 districts of Terai region and 11 states of India. Vulnerability was calculated using a following categorical classification: movement to forests and development areas is frequent (high risk); visit to forest is infrequent but visit to high-risk areas is frequent (moderate risk), movements to above areas are infrequent but to endemic areas in Nepal or India are frequent (low risk), and movement to non-endemic areas only (no risk) (Table 2).

Operational definition of risk $(R)$ was formulated to categorize and draw conclusions on malaria risk. Overall score ranged from 0 to 100 , which was classified into four categories based on the operational definition.
$R=(0.3 \mathrm{~S} 1+0.5 \mathrm{~S} 2+0.2 \mathrm{~S} 3) \times 100$, where $\mathrm{S} 1, \mathrm{~S} 2$, and S3 are the scores for API, entomology, and vulnerability, respectively, which were scored 0 for no risk, 0.1 for low risk, 0.6 for moderate risk, and 1 for high risk. The overall risk was classified into 4 classes: $0-20 \%$, no risk; $20-50 \%$, low risk; $50-80 \%$, moderate risk; and 80-100\%, high risk.

\section{Results}

Malaria risk was stratified up to the VDC level on the basis of overall scores of the three major variables: disease burden, ecology/vector transmission, and vulnerabilitypopulation movement. VDCs were classified into four categories: no risk, low risk, moderate risk, and high risk (Table 3).

\section{Disease burden}

Of the total VDCs $(n=3976 ; 4$ excluded for missing values), 44 (1.10\%) reporting API-a $\geq 1,752$ (18.91\%) reporting API-a $=0.01-0.99$, and 3176 (79.88\%) reporting API-a $=0$ (no malaria cases) were respectively classified as high-, moderate-, and low-burden VDCs based on a 3-year analysis (2009 to 2011) (Fig. 4). VDCs with high, moderate, and low burden received a response value of $1.0,0.6$, and 0.1 , respectively.

Table 3 Village Development Committees (VDCs) and risk population by development regions in Nepal

\begin{tabular}{|c|c|c|c|c|c|c|c|c|c|c|c|}
\hline \multirow[t]{2}{*}{ Region } & \multirow{2}{*}{$\begin{array}{l}\text { Number } \\
\text { of } \\
\text { districts }\end{array}$} & \multicolumn{2}{|c|}{ High risk } & \multicolumn{2}{|c|}{ Moderate risk } & \multicolumn{2}{|c|}{ Low risk } & \multicolumn{2}{|c|}{ No risk } & \multicolumn{2}{|c|}{ Total VDC } \\
\hline & & VDC & Population $^{1}$ & VDC & Population $^{1}$ & VDC & Population $^{1}$ & VDC & Population $^{1}$ & VDC & Population $^{1}$ \\
\hline Eastern & 16 & 0 & 0 & 24 & 430,773 & 215 & $2,511,297$ & 668 & $3,235,282$ & 907 & $6,177,352$ \\
\hline Central & 19 & 10 & 258,959 & 77 & 927,902 & 353 & $2,821,865$ & 778 & $5,675,767$ & 1218 & $9,684,493$ \\
\hline Western & 16 & 7 & 115,595 & 27 & 372,822 & 191 & $1,881,278$ & 652 & $2,661,812$ & 877 & $5,031,507$ \\
\hline Mid-western ${ }^{2}$ & 15 & 18 & 246,740 & 59 & 692,140 & 92 & 883,228 & 412 & $1,767,651$ & 581 & $3,589,759$ \\
\hline Far-western & 9 & 19 & 364,342 & 14 & 237,055 & 148 & $1,281,067$ & 208 & 799,408 & 389 & $2,681,872$ \\
\hline Grand Total ${ }^{2}$ & 75 & 54 & 985,636 & 201 & $2,660,692$ & 999 & $9,378,735$ & 2718 & $14,139,920$ & 3976 & $27,164,983$ \\
\hline
\end{tabular}

${ }^{1}$ VDC population is supplied by DPHO/DHO or else taken from census 2011, CBS

${ }^{2} \mathrm{VDC}$ with missing population is not included in the analysis

VDC Village Development Committees, DPHO/DHO District Public Health Office/District Health Office, CBS Central Bureau of Statistics 


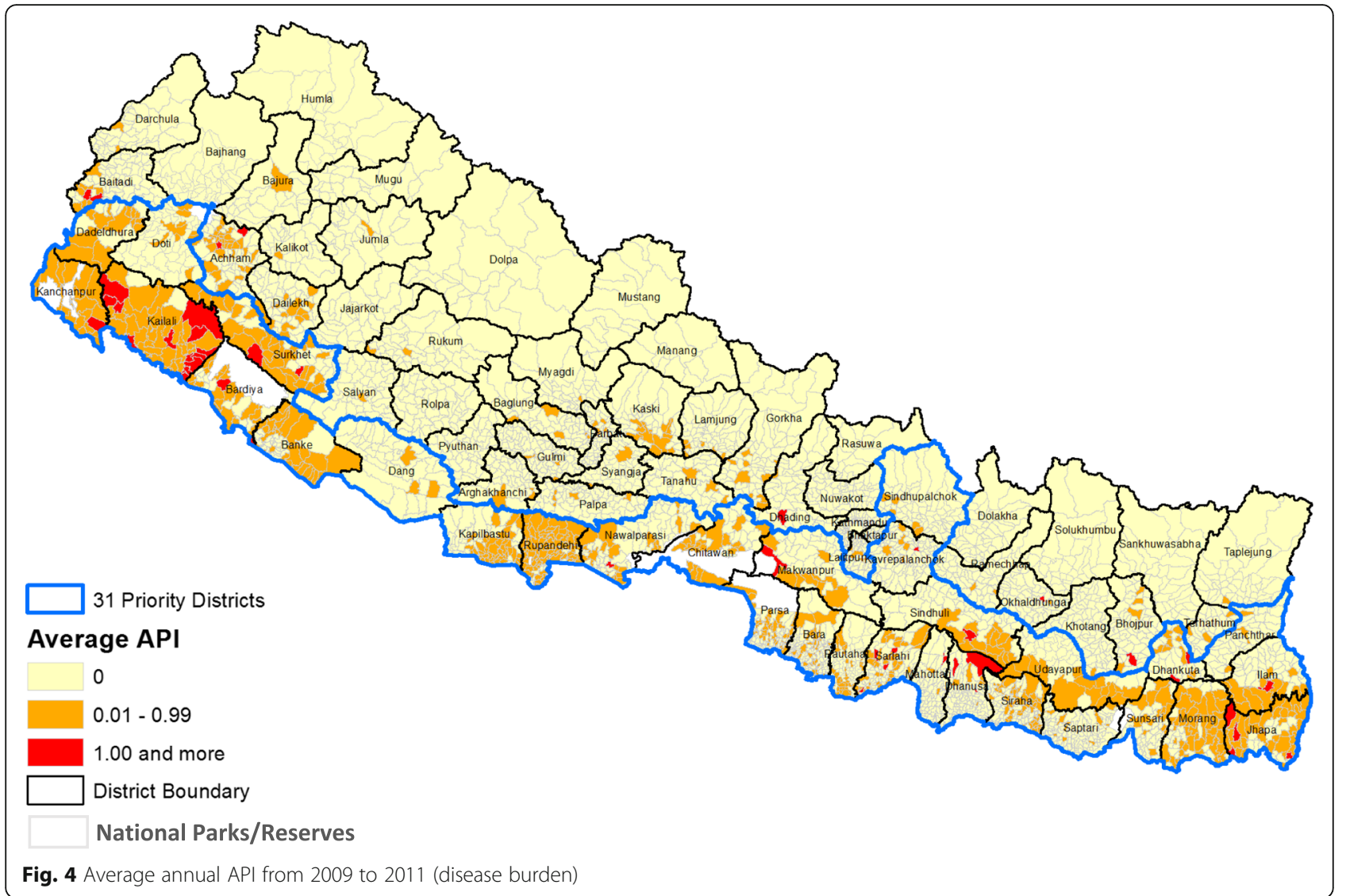

\section{Entomological risk/ecology}

Entomological risk was derived based on the historical evidences (Table 1) using the combination of ecological zones (five ecological settings), land-use pattern, and trend of malaria cases analyzed in GIS environment. Altogether, 97 (2.44\%), 206 (5.18\%), and 3665 (92.18\%) VDCs were respectively classified as high, moderate, and low transmission potential. Upon further refinement based on land use, the outer Terai showed two distinct high and low transmission potential areas that included forest and cultivated areas (Fig. 5). Inner Terai showed high and moderate transmission potential, leaving the rest of the three ecological settings under low transmission potential. Output refinement in the inner Terai yielded two categories: high (VDCs having cases in all 3 years) and moderate transmission potential (cases in any of the 3 years). Interestingly, this refinement changed $23(1.17 \%)$ inner Terai VDCs from moderate to high transmission potential.

\section{Vulnerability}

There were 686 (17.25\%) and 3290 (82.75\%) VDCs under high and low vulnerability, respectively, but none of the VDCs were moderate and non-vulnerable (Fig. 6).

\section{Overall risk}

Analyzing the overall risk based on scoring (disease burden, 0.3 wt.; ecology, 0.5 wt.; and vulnerability, 0.2 wt.) of the total VDCs $(n=3976), 54(1.36 \%), 201(5.06 \%), 999(25.13 \%)$, and 2718 (68.36\%) VDCs were identified as high-, moderate-, low-, and no-risk categories for malaria, respectively (Fig. 7).

Based on the population statistics, $3.62 \%(985,636 /$ 27,164,983), 9.79\% (2,660,692/27164983), 34.52\% (9,378,735/ $27164983)$, and $52.05 \%(14,139,920 / 27164983)$ of the country's total population live in high-, moderate-, low-, and no-risk VDCs, respectively. Regional distribution showed that the majority of the high-risk VDCs (1918 VDCs) were identified in the Far- and Mid-western regions followed by Central and Western regions (107 VDCs) with no high-risk VDC in the Eastern region. Similarly, 77, 59, 27, 24, and 14 VDCs of the Central, Mid-western, Western, Eastern, and Far-western regions, respectively, were found to be under moderate malaria risk. Of the low-risk VDCs, 353, 215, 191, 148, and 92 were respectively from Central, Eastern, Western, Far-western, and Mid-western regions (Table 3).

\section{Discussion}

With the significant reduction of malaria cases in recent years, the malaria control program in Nepal has set up 


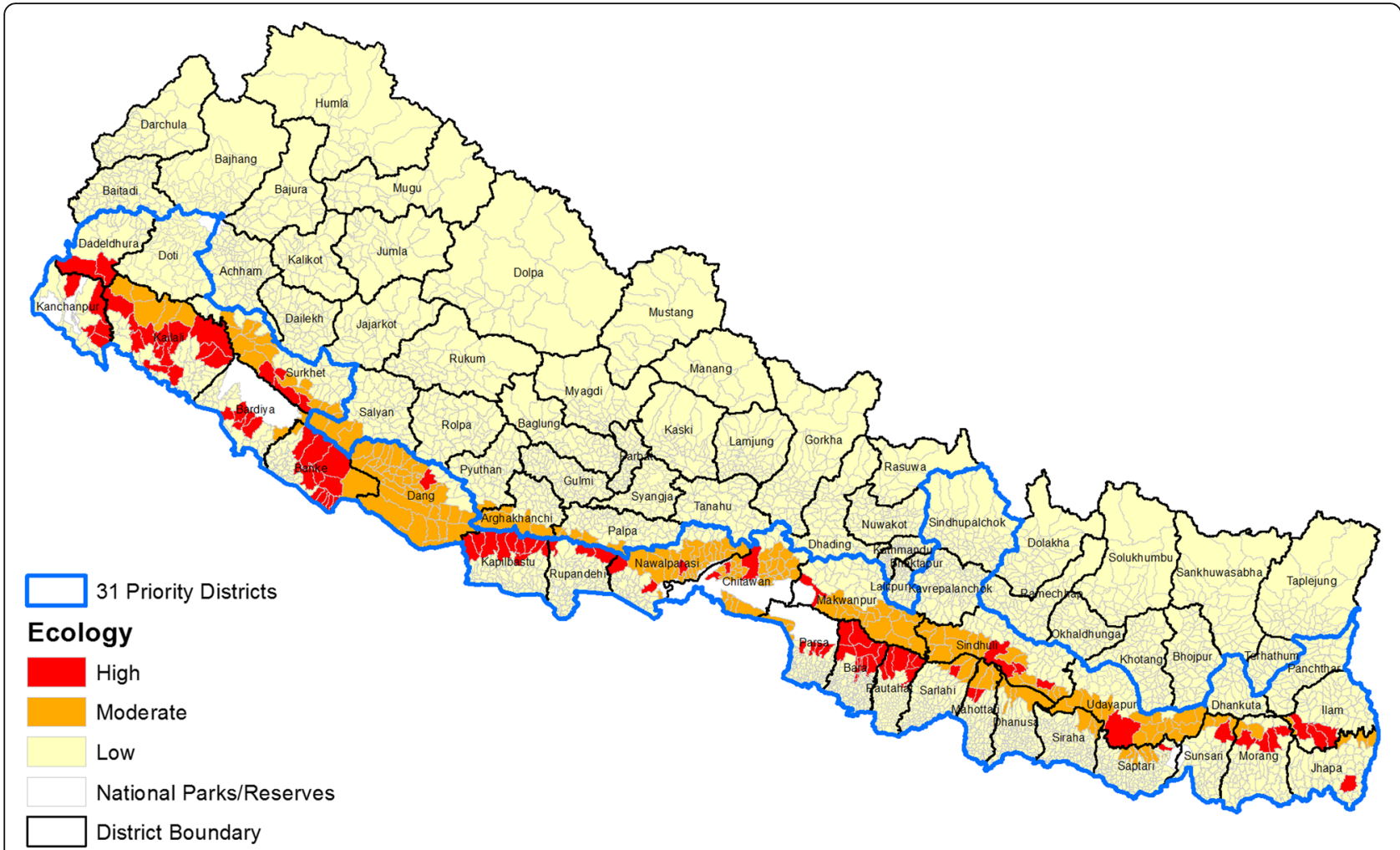

Fig. 5 Entomological risk of malaria transmission (Ecology)

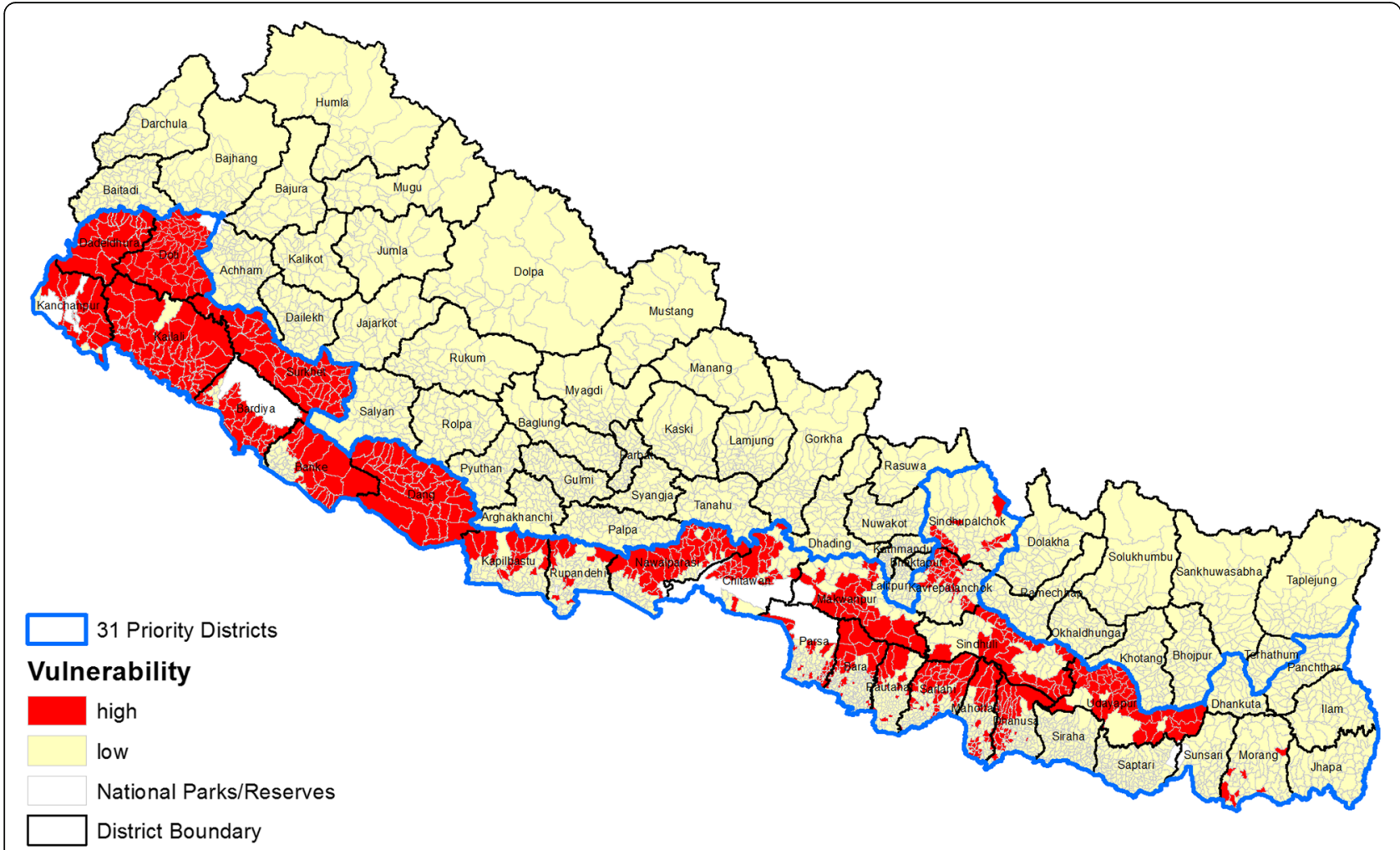

Fig. 6 Vulnerability due to population movement 


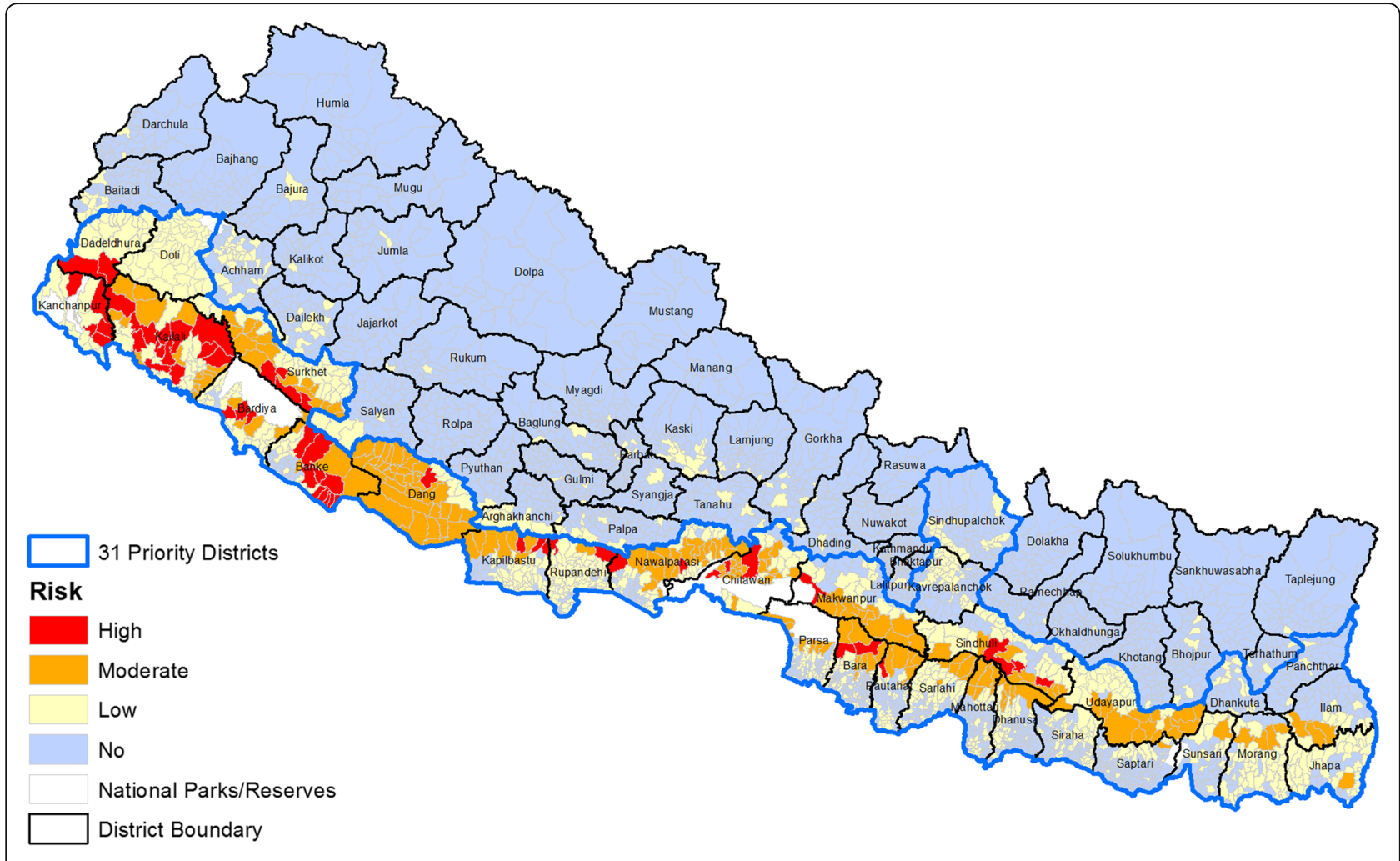

Fig. 7 Village Development Committee (VDC) level malaria risk in Nepal

the vision of "a malaria-free Nepal by 2025" and the country is currently in the pre-elimination phase (Table 4) [5, 15]. Malaria risk mapping by micro-stratification up to the VDC level is critical in order to deploy appropriate and tailored malaria control interventions to achieve the targeted goal of elimination. Micro-stratification helps to highlight the distribution and potential impact of multiple disease interventions [16]. This approach should be used more widely over time and space and at different geographical scales to better monitor and understand the impact of single and multiple interventions and to assess progress towards the elimination of different diseases [17]. Although not commonly practiced in malaria control programs, such an approach is necessary for national

Table 4 Recommended interventions per stratum for Nepal malaria program

\begin{tabular}{|c|c|c|c|c|}
\hline Interventions & High risk & Moderate risk & Low risk & $\begin{array}{l}\text { No } \\
\text { risk }\end{array}$ \\
\hline LLINS & $\begin{array}{l}\text { First priority; limited to wards with } \\
\text { indigenous cases and adjacent wards within } \\
2-3 \mathrm{~km}\end{array}$ & $\begin{array}{l}\text { Second priority; limited to wards with } \\
\text { indigenous cases adjacent wards within } \\
2-3 \mathrm{kms}\end{array}$ & $\begin{array}{l}\text { Third priority; limited to households } \\
\text { with confirm cases only to prevent } \\
\text { transmission }\end{array}$ & NA \\
\hline IRS & $\begin{array}{l}\text { Focal; } 1-2 \text { cycles depending on the duration } \\
\text { of transmission and residual efficacy of } \\
\text { insecticide }\end{array}$ & Yes; to contain outbreak & Yes, to contain outbreak & NA \\
\hline $\begin{array}{l}\text { Larval } \\
\text { control }\end{array}$ & As appropriate & As appropriate & As appropriate & NA \\
\hline EDPT & Yes & Yes & Yes & Yes \\
\hline $\begin{array}{l}\text { Case } \\
\text { investigation }\end{array}$ & Yes & Yes & Yes & Yes \\
\hline $\begin{array}{l}\text { Foci } \\
\text { investigation }\end{array}$ & Yes, second priority & Yes, first priority & $\begin{array}{l}\text { No, except when indigenous case is } \\
\text { reported }\end{array}$ & NA \\
\hline $\mathrm{BCC}$ & Yes & Yes & Yes & Yes \\
\hline
\end{tabular}

LLINs long-lasting insecticide-treated nets, IRS indoor residual spraying, EDPT early diagnosis and prompt treatment, $B C C$ behavioral change communication, $\mathrm{km}$ kilometers, NA not applicable 
planning purposes as well as increasing the cost effectiveness and coordination of malaria elimination programs where different strategies are deployed.

The application of micro-stratification to control diseases has been increasingly adopted in recent years. For example, micro-stratification has been utilized in malaria control and elimination program in Timor Leste [18]. In Philippines, micro-stratification has been applied to control and eliminate vector-borne diseases such as dengue and malaria [19].

The malaria risk stratification in Nepal considers several key determinants of malaria transmission, for example, disease burden (API-malaria cases per 1000 risk population) in the last 3 years, ecology that determines the presence of the vectors, relative efficiency of the vectors in malaria transmission, duration of transmission in ecological zones, and vulnerability in terms of population movement. The key determinants (termed as major variables) are given weights to stratify the malaria risk. This method has been used to control lymphatic filariasis in the Democratic Republic of Congo [20] and Nigeria [16]. Overall, the stratification of malaria risk areas is robust enough to be used for the planning and implementation of key interventions [21]. This information is a prerequisite for effective planning and will help to appropriate the elimination strategy to ensure targeted coverage to be cost effective with maximum impact $[11,18]$.

In the context of Nepal, there is a large variation in topography and ecology in many of the VDCs. VDC, as a unit of the study, may have generalized these variations. Stratification by a VDC comprises several wards and villages. However, in Nepal, there was no systematic malaria risk assessment and the previous risk assessments were limited to district level [22]. The current micro-stratification provides the insight of malaria risk at VDC level. This will help the Malaria Elimination Program to target interventions at the VDC level, thereby ensuring the best utilization of available resources to substantially narrowed-down target areas [16]. In neighboring country Bangladesh, mapping the stability of malaria hotspots has been under operation to achieve the goal of informing intervention planning for malaria elimination [23].

In many areas of Nepal, there are other diseases which are co-endemic with malaria. Therefore, micro-stratification can also be used as an integrated approach to facilitate multiple disease control and elimination such as lymphatic filariasis. In African settings, such an approach has been found greatly effective in planning and implementing the programs against co-endemic conditions such as loiasis and filariasis [20]. Current micro-stratification of malaria work builds on the recent study carried out in the Democratic Republic of Congo [20], which used the new overlap mapping approach to collate and map all available country data on Wuchereria bancrofti, examine the extent of Loa loa co-endemicity, and determine the risk and benefits of different intervention strategies.

\section{Implications for malaria control and elimination}

Malaria control and elimination strategies are being accelerated in Southeast Asia and the Greater Mekong region and have mainly focused to halt the spread of artemisinin resistance using multiple control measures such as mass drug administration for malaria hotspots, strengthening village malaria workers, and deployment of LLINs with community engagement strategies wherein community members are trained and devolved with the responsibilities in the malaria risk areas which can be enhanced by malaria micro-stratification study [24-32]. Even though a recent study from Nepal has not yet shown the artemisinin resistance against P. falciparum in Nepal, a continuous monitoring for resistance markers was recommended to be critical [15]. In addition, studies from Nepal have shown $P$. vivax as a dominating species for the last 50 years [5]. In recent years, malaria vectors have been isolated in the hilly regions of Nepal, which previously were devoid of vectors for malaria [22, 33]. The control and elimination of malaria, therefore, needs to target species-specific interventions integrating the current elimination program [34]. For the complete elimination of malaria (including $P$. vivax), a radical therapy using primaquine is essential. Nevertheless, administration of radical therapy using primaquine requires G6PD deficiency testing [35-37]. Although the current study focused on $P$. falciparum, future micro-stratification study can benefit by expanding micro-stratification by species as well. In order to target the malaria risk areas (low-, moderate-, and high-risk areas for malaria) identified by the current micro-stratification study, community engagement strategies might be beneficial to intensify malaria control activities [24, 25, 31, 38].

\section{Limitations}

The entomological information integrated into this study is not up to date. There is no current study conducted in entomology. Over the years, there is a massive scale of ecological changes including high usage of insecticides that can yield changes in vector bionomics. The analysis is based on historical evidences only. There are no baseline entomological studies of the Himalayan mountain districts, and it is presumed that there are no malaria vectors present in the region due to the climatological factors and based on the history of no evidence of malaria transmission. 
A large number of missed clinical cases may have been underestimated in this study to classify the areas with malaria risk. This study did not include cases from private facilities.

\section{Conclusion}

The current micro-stratification estimates the population at risk of malaria has decreased to 13.02 million from 20.35 million over the past 5 years. This study has re-defined the malaria risk and re-mapped it more systematically. Findings from this study can aid in utilizing the available resources to substantially narrowed-down target areas. In future, micro-stratification can be employed to further identify the risk areas into smaller units within the VDCs such as wards and villages.

\section{Abbreviations}

API: Annual Parasite Index; BCC: Behavioral change communication; CBS: Central Bureau of Statistics; CDC: Center for Disease Control and Prevention; DHO: District Health Office; DPH: District Public Health Office; EDCD: Epidemiology and Disease Control Division; EDPT: Early diagnosis and prompt treatment; GIS: Geographical information system; GPS: Global Positioning System; HMIS: Health Management Information System; ICIMOD: International Centre for Integrated Mountain Development; IRS: Indoor residual spraying; LLINs: Long-lasting insecticide-treated Nets; NMP: National Malaria Program; RDT: Rapid diagnostic test; SOPs: Standard operating procedures; VBDRTC: Vector Borne Disease Research and Training Center; VDC: Village Development Committee; WHO: World Health Organization

\section{Acknowledgements}

The authors like to thank Late malariologist Dr. Manas Kumar Banarjee for his great help to conduct this study. We are very much grateful to the team of EDCD/ Ministry of Health and Population and World Health and Research Center, Kathmandu, Nepal. Authors are also thankful to the DHO/ DPHO, MIS Section of Management Division in making available the necessary data and support, and Regional Advisor, SEARO, the team leaders and the members of the independent Regional Teams for data collection and verification, review and valuable comments and suggestions. We are thankful to Mr. Rajendra Mishra, Mr. Ajoy Thakur, Mr. Hemraj Joshi, Mr. Shishir Pant, Mr. Shambhunath Jha for their help in data collection. We would like to express our gratitude to Gordan Tambell, USA for proof reading and edits. This study was financially supported by WHO Country Office, Nepal. We are grateful to Mr. Gordon Tambellini for his edits and constructive review.

\section{Funding}

The study was funded by WHO country office operational research funds for malaria program.

\section{Availability of data and materials}

All data pertaining to this study are within the manuscript.

\section{Authors' contributions}

PG, LO, NS, and GDT conceptualized the study/activity. KRR and PG designed the tools for data collection. KRR, BA, PG, NS, BKL, and GDT stored, curated, and analyzed the data. KRR, NA, UTS, and SPD drafted the manuscript. PG, $M S B, M R B$, and $B A$ reviewed and provided the initial feedback for revision by all the authors. PG, KRR, and BA revised and edited the subsequent versions of the manuscript. All authors read and approved the final version of the manuscript.

\section{Ethics approval and consent to participate}

This study utilized a retrospective analysis of data collected as a part of National Malaria Control and elimination strategy. Additionally, since this study does not include any data directly related to human subjects, the study was exempted for ethical permissions. This was a national study, and taken approval from Epidemiology and Diseases Control Division,
Department of Health services, Ministry of Health and Population, government of Nepal.

\section{Consent for publication}

Not applicable.

\section{Competing interests}

The authors declare that they have no competing interests.

\section{Publisher's Note}

Springer Nature remains neutral with regard to jurisdictional claims in published maps and institutional affiliations.

\section{Author details}

${ }^{1}$ Central Department of Microbiology, Tribhuvan University, Kirtipur, Kathmandu, Nepal. ${ }^{2}$ Centre for Tropical Medicine and Global Health, Nuffield Department of Medicine, University of Oxford, Oxford, UK. ${ }^{3}$ Department of Immunogenetics, Institute of Tropical Medicine (NEKKEN), Nagasaki University, Nagasaki, Japan. ${ }^{4}$ World Health and Research Centre, Kathmandu, Nepal. ${ }^{5}$ World Health Organization (WHO), Country Office, Kathmandu, Nepal. ${ }^{6}$ Global Malaria Program, World Health Organization Headquarters, Geneva, Switzerland. 'Epidemiology and Disease Control Division (EDCD), Department of Health Services, Ministry of Health and Population, Kathmandu, Nepal.

Received: 4 January 2019 Accepted: 14 March 2019

Published online: 27 March 2019

\section{References}

1. WHO Global Malaria Program. World malaria report 2017. Switzerland: WHO Press, World Health Organization. Available at: http:/www.who.int/malaria/ publications/world-malaria-report-2017/en/. Accessed February 11, 2018

2. WHO Global Malaria Program. World malaria report 2016. Switzerland: WHO Press, World Health Organization. Available at: http:/www.who.int/malaria/ publications/world-malaria-report-2016/en/. Accessed February 15, 2018

3. World Health Organization. Global malaria control and elimination: report of a technical review. Geneva: WHO; 2008.

4. WHO Global Malaria Program. World malaria report 2013. Switzerland: WHO Press, World Health Organization. Available at: http://www.who.int/malaria/ publications/world-malaria-report-2013/en/. (Accessed February 11, 2018)

5. Rijal KR, Adhikari B, Ghimire P, Banjara MR, Hanboonkunupakarn B, Imwong $M$, et al. Epidemiology of Plasmodium vivax malaria infection in Nepal. Am J Trop Med Hyg. 2018;99(3):680-7.

6. EDCD (Epidemiology and Diseases Control Division): Nepal Malaria Strategic Plan 2014-2025. Department of Health Services, Ministry of Health and Population, Government of Nepal; 2017. Avialable online at: http://www. edcd.gov.np/publications.html (Acessed 25 Jan, 2018).

7. World Health Organization. Global technical strategy for malaria: accelerating progress towards elimination. Web consultation version, 9 July 2014, WHO

8. EDCD (Epidemiology and Diseases Control Division): Nepal Malaria Strategic Plan 2011-2016 (Revisied Version, December 2011), Department of Health Services, Ministry of Health and Population, Government of Nepal; 2011. Avialable online at: http://static1.1.sqspcdn.com/static/f/471029/20810332/ 1351638302043/Nepal+Strategic+Plan+2011-1016.pdf?token= nWYAdQ7Y9YMVXOydfBODxHdOxFQ\%3D (Accessed on 15 Jan, 2018)

9. World Health organization: Nepal Malaria Programme Review: June, World Health organization, Regional office for south-east Asia., 2010. Aviable online at: http://apps.searo.who.int/PDS_DOCS/B4673.pdf. (Accessed on 20 Jan, 2018).

10. Schapira A, Boutsika K. Malaria ecotypes and stratification. Adv Parasitol. 2012;78:97-167.

11. Cox J, Sovannaroth S, Dy Soley L, Ngor P, Mellor S, Roca-Feltrer A, et al. Novel approaches to risk stratification to support malaria elimination: an example from Cambodia. Malar J. 2014:13:371.

12. WHO. Report of the informal consultation on stratification for planning antimalaria action. Geneva: World Health Organization; 1985.

13. Evaluation of Malaria Risk Microstratification Strategy, UNICEF Myanmar, 2010. Available online at: https://www.unicef.org/evaldatabase/index_67786. html. Accessed 22 Mar 2019 
14. Center for Disease Control and Prevention. National public health performance standards program. Office of the Director, CDC; 2014. [Accessed: December 11, 2014] Available from http://www.cdc.gov/od/ ocphp/nphpsp/

15. Ghimire P, Rijal KR, Kafle C, Karki BS, Singh N, et al. Efficacy of artemetherlumefantrine for the treatment of uncomplicated Plasmodium falciparum malaria in Nepal. Trop Dis Travel Med Vaccines. 2018;4:9.

16. Okorie PN, Ademowo GO, Saka Y, Davies E, Okoronkwo C, Bockarie MJ, et al. Lymphatic filariasis in Nigeria; micro-stratification overlaps mapping (MOM) as a prerequisite for cost-effective resource utilization in control and surveillance. PLoS Negl Trop Dis. 2013;7(9):e2416.

17. Amazigo UV, Leak SG, Zoure HG, Njepuome N, Lusamba-Dikassa PS. Community-driven interventions can revolutionise control of neglected tropical diseases. Trends Parasitol. 2012;28(6):231-8.

18. Yapabandara MA, Sarmento R, de Fatima Mota Mdo R, don Bosco J, Martins $\mathrm{N}$, Wickremasinghe AR, et al. Evidence-based malaria control in Timor Leste from 2006 to 2012. Malar J. 2015;14:109.

19. van den Berg $H$, Velayudhan $R$, Ebol $A$, Catbagan $B H$, Jr Turingan $R$, et al. Operational efficiency and sustainability of vector control of malaria and dengue: descriptive case studies from the Philippines. Malar J. 2012;11:269.

20. Kelly-Hope LA, Thomas BC, Bockarie MJ, Molyneux DH. Lymphatic filariasis in the Democratic Republic of Congo; micro-stratification overlaps mapping (MOM) as a prerequisite for control and surveillance. Parasit Vectors. 2011;4:178.

21. Beier JC, Keating J, Githure JI, Macdonald MB, Impoinvil DE, Novak RJ. Integrated vector management for malaria control. Malar J. 2008;7 Suppl 1:S4.

22. Dhimal M, O'Hara RB, Karki R, Thakur GD, Kuch U, Ahrens B. Spatio-temporal distribution of malaria and its association with climatic factors and vectorcontrol interventions in two high-risk districts of Nepal. Malar J. 2014;13:457.

23. Noe A, Zaman SI, Rahman M, Saha AK, Aktaruzzaman MM, Maude RJ. Mapping the stability of malaria hotspots in Bangladesh from 2013 to 2016. Malar J. 2018;17(1):259

24. Adhikari B, Phommasone $K$, Pongvongsa $T$, Kommarasy P, Soundala $X$, Henriques $G$, et al. Factors associated with population coverage of targeted malaria elimination (TME) in southern Savannakhet Province, Lao PDR. Malar J. 2017;16:424.

25. Adhikari B, Phommasone K, Kommarasy $P$, Soundala $X$, Souvanthong $P$, Pongvongsa $T$, et al. Why do people participate in mass anti-malarial administration? Findings from a qualitative study in Nong District, Savannakhet Province, Lao PDR (Laos). Malar J. 2018;17:15.

26. Peto TJ, Tripura R, Sanann N, Adhikari B, Callery J, Droogleever M, Heng C, Cheah PY, Davoeung C, Nguon C, et al. The feasibility and acceptability of mass drug administration for malaria in Cambodia: a mixed-methods study. Trans R Soc Trop Med Hyg. 2018;112:264-71.

27. von Seidlein L, Dondorp A. Fighting fire with fire: mass antimalarial drug administrations in an era of antimalarial resistance. Expert Rev Anti-Infect Ther. 2015;13:715-30.

28. Tripura R, Peto TJ, Chea N, Chan D, Mukaka M, Sirithiranont P, Dhorda M, Promnarate C, Imwong M, von Seidlein L, et al. A Controlled Trial of Mass Drug Administration to Interrupt Transmission of Multidrug-Resistant Falciparum Malaria in Cambodian Villages. Clin Infect Dis. 2018;67:817-26.

29. Landier J, Parker DM, Thu AM, Lwin KM, Delmas G, Nosten FH. Effect of generalized access to early diagnosis and treatment and targeted mass drug administration on Plasmodium falciparum malaria in Eastern Myanmar: an observational study of a regional elimination programme. Lancet. 2018; 391(10133):1916-26

30. Adhikari B, James N, Newby G, von Seidlein L, White NJ, Day NP, et al. Community engagement and population coverage in mass anti-malarial administrations: a systematic literature review. Malar J. 2016;15:523.

31. Adhikari B, Pell C, Phommasone K, Soundala X, Kommarasy P, Pongvongsa $T$, Henriques G, Day NPJ, Mayxay M, Cheah PY. Elements of effective community engagement: lessons from a targeted malaria elimination study in Lao PDR (Laos). Glob Health Action. 2017;10:1366136.

32. Kajeechiwa L, Thwin MM, Nosten S, Tun SW, Parker D, von Seidlein $L$, et al. Community engagement for the rapid elimination of malaria: the case of Kayin State, Myanmar. Wellcome Open Res. 2017;2:59.

33. Dhimal M, Ahrens B, Kuch U. Malaria control in Nepal 1963-2012: challenges on the path towards elimination. Malar J. 2014;13:241.

34. Lover AA, Baird JK, Gosling R, Price RN. Malaria elimination: time to target all species. Am J Trop Med Hyg. 2018;99(1):17-23.
35. Ghimire P, Singh N, Ortega L, Rijal KR, Adhikari B, Thakur GD, et al. Glucose6-phosphate dehydrogenase deficiency in people living in malaria endemic districts of Nepal. Malar J. 2017;16:214.

36. Henriques G, Phommasone K, Tripura R, Peto TJ, Raut S, Snethlage C, et al. Comparison of glucose- 6 phosphate dehydrogenase status by fluorescent spot test and rapid diagnostic test in Lao PDR and Cambodia. Malar J. 2018;17(1):243.

37. Tripura R, Peto TJ, Chalk J, Lee SJ, Sirithiranont P, Nguon C, et al. Persistent Plasmodium falciparum and Plasmodium vivax infections in a western Cambodian population: implications for prevention, treatment and elimination strategies. Malar J. 2016;15:181.

38. Takahashi E, Nonaka D, Iwagami M, Phoutnalong V, Chanthakoumane K, Kobayashi J, et al. Patients' adherence to artemisinin-based combination therapy and health care worker's perception and practice in Savannakhet province. Trop Med Health. 2018:46:44.
Ready to submit your research? Choose BMC and benefit from:

- fast, convenient online submission

- thorough peer review by experienced researchers in your field

- rapid publication on acceptance

- support for research data, including large and complex data types

- gold Open Access which fosters wider collaboration and increased citations

- maximum visibility for your research: over $100 \mathrm{M}$ website views per year

At $\mathrm{BMC}$, research is always in progress.

Learn more biomedcentral.com/submissions 